\title{
Port-en-Bessin-Huppain - Le Mont Castel
}

$\mathrm{n}^{\circ} 3397$

Jean-Paul Guillaumet

\section{(2) OpenEdition}

Journals

Édition électronique

URL : http://journals.openedition.org/adlfi/17014

ISSN : 2114-0502

Éditeur

Ministère de la culture

Référence électronique

Jean-Paul Guillaumet, "Port-en-Bessin-Huppain - Le Mont Castel », ADLFI. Archéologie de la France -

Informations [En ligne], Basse-Normandie, mis en ligne le 16 mars 2016, consulté le 20 avril 2019.

URL : http://journals.openedition.org/adlfi/17014

Ce document a été généré automatiquement le 20 avril 2019

(c) Ministère de la Culture et de la Communication, CNRS 


\title{
Port-en-Bessin-Huppain - Le Mont Castel
}

$\mathrm{n}^{\circ} 3397$

\author{
Jean-Paul Guillaumet
}

Lien Atlas (MCC) :

http://atlas.patrimoines.culture.fr/atlas/trunk/index.php?

ap_theme=DOM_2.01.02\&ap_bbox=-0.801;49.324;-0.744;49.353

Le travail de cette année a été de réaliser une enquête sur la plaine fermée de Port-enBessin, particularité géologique remarquable, et ses occupations humaines. Il a consisté en une recherche documentaire de tous les éléments liés à la topographie du site, les découvertes anciennes et les travaux en géologie et en géoarchéologie dans les archives et les publications. Ce travail s'est déroulé dans les bibliothèques, les archives et sur internet. Il a abouti à l'élaboration de fiches récapitulatives pour les documents graphiques les plus importants. Tous ces documents ont été ensuite analysés et critiqués pour établir une problématique globale sur la plaine fermée. En parallèle, de nombreuses sorties sur le terrain ont permis une première validation de nos hypothèses. Tous ces travaux avaient pour but de remettre dans son environnement naturel et humain le site $\mathrm{du}$ Mont Castel, premier oppidum à vocation portuaire mis en évidence sur la côte du Calvados. Les résultats ont dépassé nos espérances et nous ont renforcés dans l'idée de lancer un projet global sur la plaine fermée et ses abords. Plusieurs pistes ont été privilégiées et permettent de proposer plusieurs axes de recherche.

2 Les travaux en rapport avec la géologie avaient pour but :

- d'évaluer l'évolution du trait de côte. À partir des données obtenues sur les cinquante dernières années, la surface disparue du Mont Castel depuis trois mille ans serait d'environ cinquante hectares, soit deux fois la surface actuelle. Si l'on projette ce calcul sur le front de mer du Mont Huppain, on obtient un passage de la mer à la plaine de plusieurs centaines de mètres à l'époque protohistorique ;

- d'étudier les pertes de l'Aure et son impact sur la plaine fermée.

La plaine fermée présente actuellement un déficit en ressources d'eau. Grâce aux plans et 
études des courbes de niveau, nous avons pu y mettre en évidence l'existence d'un réseau hydrographique complexe. Ces cours d'eau, dont les derniers disparaissent au XVII ${ }^{\mathrm{e}}$ s., sont liés à des résurgences des pertes de l'Aure ;

- étudier le passage plateau-plaine fermée.

La plaine fermée et les hauteurs qui l'enserrent sont un seul ensemble fermé par des défenses naturelles, renforcées par des fortifications aux endroits les plus faibles dont nous avons pu repérer une partie. La découverte, au pied des deux sites occupés dès l'âge du Bronze, de rempart avec porte en chicane, est un élément encourageant pour la suite de la recherche ;

- quantifier les données archéologiques en notre possession.

Les données archéologiques de la plaine fermée montrent une occupation sur une partie des hauteurs et une absence de site dans la partie basse. Les périodes les mieux reconnues actuellement sont la fin de l'âge du Bronze, le Hallstatt et La Tène. Pour cette dernière période, il s'agit d'une occupation très tardive de la deuxième moitié du $\mathrm{I}^{\mathrm{er}} \mathrm{s}$. av. J.-C. Ce qui est considéré comme de l'époque romaine est infime et doit correspondre en partie à l'Antiquité tardive et au premier Moyen Âge. L'occupation de l'âge du Bronze semble la plus prometteuse avec la découverte de remparts et de portes de même type sur les monts Cavalier et Castel ;

- réaliser l'historique des installations portuaires.

Les textes sur l'apparition et le fonctionnement de la zone du port actuel montrent une forte orientation des maigres données pour conforter des hypothèses flatteuses pour le site, mais peu étayées. La structuration actuelle de cette ouverture entre le Mont Castel et le Mont Huppain a toujours fait penser que ce lieu est un port avec bassin depuis l'Antiquité. Le terme portus, utilisé pour désigner ce lieu à l'époque antique d'après les érudits, semble donner une argumentation de poids à cette tradition. Les premiers éléments recueillis de la circulation de l'eau dans la plaine fermée montrent l'existence de cours d'eau dont l'estuaire est la zone du port actuel. Le rôle du pont qui permet de relier les deux rives puis d'amarrer les bateaux et peut-être aussi de servir de barrage pour stocker une réserve d'eau reste mystérieux. Ainsi, on ignore ce que dessert la route franchissant cet ouvrage en pierre monumentale ainsi que sa date de construction, ses reprises et modifications. Ces premières constatations nous poussent à proposer de continuer ces recherches en archives, complément indispensable au travail de terrain.

3 Dans l'état des données à notre disposition, le premier port construit attesté avec certitude est le bassin en mer, construit vers les années 1850, suivi par les travaux du premier bassin intérieur. La voirie Bayeux-Port est ensuite totalement refaite entre la fin du XVIII ${ }^{\mathrm{e}}$ s. et le début du XIX ${ }^{\mathrm{e}} \mathrm{s}$.

Ces deux années de recherches pluridisciplinaires nous ont fait découvrir des situations complexes, des données sous-exploitées et un modèle d'organisation du territoire que nous ne connaissons que sur un seul site: Heidengraben bei Grabenstetten en Souabe. Considéré comme le plus grand oppidum celtique, 1600 hectares, cet ensemble reste un cas isolé, dont la création et le fonctionnement restent encore mystérieux (Fischer, 1971). Aussi proposons-nous l'étude de la plaine fermée et ses abords dans le cadre d'un PCR : Étude de la plaine fermée de Port-en-Bessin : de l'âge du Bronze à la fin de l'âge du Fer. 
INDEX

Index géographique : Basse-Normandie, Calvados (14), Port-en-Bessin-Huppain operation Prospection avec matériel spécialisé (PMS)

Mots-clés : oppidum, rempart, porte, route, port

\section{AUTEURS}

JEAN-PAUL GUILLAUMET

CNRS 